\title{
Optimal Maturity of Government Debt without State Contingent Bonds
}

\author{
Francisco Buera \\ University of Chicago, 1126 E 59th St. Chicago Il., 60637 \\ Juan Pablo Nicolini* \\ Universidad Di Tella, Miñones 2159, Capital Federal, 1428. Argentina. \\ First Version: January 2000. \\ This Version: January 2002.
}

\begin{abstract}
This paper shows that state contingent debt can be syntethically constructed using non-contingent debt of different maturities. A main policy implication of this principle is that the Ramsey allocation with complete markets can be sustained with non-contingent debt only by properly managing its maturity structure. The numerical experiments, however, suggest that this policy implication ought to be taken with care. We find that the debt positions that sustain the Ramsey allocation are very high (on the order of a few hundred times total GDP for a very simple four state economy) and increasing in the number of states. In addition, they are very sensitive to small variations in the parameters of the model.
\end{abstract}

*Corresponding author: Juan P. Nicolini. Department of Economics, Universidad Torcuato Di Tella, Miñones 2159, Capital Federal, 1428. Argentina. Tel: 54-11-4784-0080. Fax: 54-11-4784-0089. E-mail: juanpa@utdt.edu.

$\dagger$ We started working on this project after a lively discussion on a presentation of an earlier paper of ours in a conference on Incomplete Markets organized by the Federal Reserve Bank of Minneapolis. We want to thank the participants for the discussion. We also want to thank two referees, Fernando Alvarez, Christian Broda, Albert Marcet, Rodi Manuelli, Andy Neumeyer and Iván Werning for helpful conversations. We acknowledge research support from Latin American Research Network of the Inter-American Development Bank. We alone are responsible for shortcomings. 
Keywords: Government Debt, Optimal Maturity Structure JEL: H63, H21. 


\section{Introduction}

In this paper we explore the ability of the maturity structure of public debt to replicate the welfare enhancing properties of state contingent debt in dynamic stochastic optimal taxation Ramsey problems ${ }^{1}$. We first study the theoretical conditions under which the complete markets Ramsey allocation can be implemented with non-contingent debt of different maturities. We then solve simple calibrated versions of the model to get a quantitative assessment of the optimal maturity structure.

On the theory side, we show that in a dynamic economy where state contingent bonds cannot be issued, a government may still implement the complete markets Ramsey allocation by issuing risk-free bonds with a rich enough menu of maturities. This result is important because it is well known that state contingent debt is an instrument to smooth distortions across states of the world and enhances welfare, but markets for these assets do not exist $^{2}$. This theoretical point is very closely related to the problem in finance of producing an asset by a combinations of existing assets. In other words, we synthetically construct state contingent debt using non-contingent debt of different maturities. In particular, we present the Ramsey problem of an infinite period stochastic model where the state has finite support. Then, we show that if the government can issue bonds with as many different maturities as the size of the support of the state, the complete markets allocation can be implemented, subject to a full rank condition on the matrix of returns.

The dependence of the term structure of interest rates on the state of the economy explains why markets can be completed with different maturities. A promise made at time $t$ to deliver one unit of consumption at $t+1$ is worth one unit of consumption in $t+1$. However, a promise made at time $t$ to deliver one unit of consumption at $t+2$ is worth the same as a one period bond in $t+1$, whose value depends on the state of nature. Thus, if one is concerned about transferring wealth from $t$ to $t+1$, a one period bond is a risk free asset, while a two period bond is a risky asset. In fact, this feature of long term debt has been exploited by Bohn (1990) with a somewhat different

\footnotetext{
${ }^{1}$ Angeletos (1999) independently worked on this same problem. His first draft is dated a few months earlier than ours.

${ }^{2}$ In fact, most goverenments mainly issue nominal debt, so, to the extent that inflation is not perfectly predictable, most debt instruments do represent contingent real assets. We further discuss this issue at the end of this introduction.
} 
purpose $^{3}$.

To complete markets, there must be as many linearly independent assets as states of nature. Thus, if the number of different maturities at a particular date, conditional on a particular state, is the same as the possible values for the states next period, and this is true for any date and state, then the economy has the same number of assets as states of nature.

A qualification to the result must be made. In order to complete markets, the existing assets need to be linearly independent, i.e., the vector of returns of different maturity bonds must be linearly independent. We show that for this to be the case, the term structure of interest rates implied by the Ramsey solution must be different across states, since it is the term structure that changes the prices of existing debt over time. Interestingly enough, though, the term structure depends on the tax rates. Thus, if at the Ramsey allocation, the vector of returns are linearly dependent, one may conjecture that by slightly changing taxes, the government may be able to approximate arbitrarily well the optimal state contingent allocation. We show this is the case if the state can take two possible values ${ }^{4}$.

In the quantitative part of the paper, we simulate a simple calibrated model to explore the properties of the optimal maturity structure of the debt. The main finding of our simulations is that debt positions are very extreme: to support the optimal allocation in a very simple economy with four states the required financial transactions amount to a few hundred times the gross domestic product each period and increases substantially with the number of states. The reason for this result is that for the calibrated versions we solve, the return on bonds of different maturities, albeit independent, are very highly correlated. Thus, spanning requires huge positions. We show the result to be very robust and not to depend on the particular calibration used. In fact, as a referee pointed out, this is consistent with the empirical literature on the term structure of interest rates $^{5}$ that showed that low dimensional affine models fit very well the data. In particular, Litterman and Scheinkman (1991) find that three factors explain $98 \%$ of the variation in yields associated with Treasury coupon bonds for one to eighteen years maturities. This is not

\footnotetext{
${ }^{3} \mathrm{He}$ tested two empirical implications of a tax smoothing model a la Barro (1979) in which different maturity bonds are used to transfer wealth between different states. He found that actively managing the maturity structure would not help much in improving tax smoothing in the US.

${ }^{4}$ Angeletos (1999) shows this is the case for any finite N.

${ }^{5}$ Cochrane (2001) offers an extensive survey.
} 
a statement regarding the ability to span many states, but it does affect the size of the positions needed for the spanning.

Our computations also show that the optimal maturity structure is very sensitive to changes in the parameters of the model that are very small, in a sense we make precise. These numerical experiments suggest that the policy implications of the equivalence result are not quite clear yet. On one hand, costly transactions may make the complete markets strategy inefficient. On the other, not very precise estimates of the true parameters of the model may provide very misleading policy advice.

The role for contingent debt as an instrument to smooth taxes across states was emphasized by Lucas and Stokey (1983). Since then, the active use of this financial instrument to increase welfare has been a key ingredient in most studies of optimal fiscal policy and optimal debt management ${ }^{6}$. In their model, if the government can fully commit to a tax policy, as we will assume in this paper, the maturity structure of the debt is irrelevant ${ }^{7}$.

More recently, Aiyagari, Marcet, Sargent and Seppala (2002) (AMSS) solve a problem similar to the one in Lucas and Stokey but assume away the possibility of state contingent debt. In their model, the government issues only one period risk free bonds. They show that the stochastic properties of the optimal taxes and the debt are very sensitive to this assumption. In particular, they show that in the economy with a full array of state contingent bonds, optimal taxes inherit the autocorrelation properties from the stochastic process of government expenditures only. On the contrary, in the economy with one period risk free bonds only, there is an additional state variable that introduces a unit root component on the solution. While Lucas and Stokey perform a purely normative exercise, AMSS do attempt a positive exercise. They argue that their model without state contingent debt fits better the experience of 18th century England, while 18th century France seems to behave more like the model with at least some state contingent bonds achieved through default. As an example of a positive exercise, Marcet and Scott (2000) compare the empirical implications of the model with complete markets, the model with just one period risk free bonds and US data. They show that the one-period risk-free bond economy replicates the qualitative features of US data much better than the complete markets economy.

\footnotetext{
${ }^{6}$ See Chari, Christiano and Kehoe (1995) and the references therein.

${ }^{7}$ Lucas and Stokey also show that a proper management of the maturity structure of the debt makes the sequence of tax rates time consistent. We abstract from time inconsistency issues in this paper.
} 
We study a barter economy without money. Thus, in our analysis, we will consider indexed bonds ${ }^{8}$. However, most governments (US and the UK being an exception together with some emerging economies) issue nominal bonds. Thus, since the inflation rate is state dependent, we may well argue that governments do issue the relevant state contingent debt. Chari et. al. (1995) explicitly considered this alternative ${ }^{9}$. Their work, however, shows that the required volatility of inflation to sustain the optimal allocation is extremely large relative to the data. Thus, even though governments could use inflation to reproduce the complete markets optimal allocation, the data suggests it is not being done. Our paper is silent with respect to why that is the case (as it is silent with respect to why governments do not use the state contingent consumption tax or, for that matter, why they do not issue state contingent bonds). Rather, our aim is to explore the potential of the term structure of the debt to do the spanning.

On the normative side, our paper shows that even though governments do not issue state contingent assets, a proper management of the debt maturity structure can, at least partially, do the job. On the positive side, our paper contributes to the literature on the properties of optimal debt and market structure. Since a wide range of maturities, as there is in real economies, approximates better than a single bond a full array of state contingent bonds, it may undo the quantitative importance of the martingale properties of the taxes obtained by Aiyagari, Marcet, Sargent and Seppala $(2002)^{10}$.

As we mentioned before, Angeletos (2002) independently obtained results very similar to the ones of this paper. Although the main insight is common, there are differences between our paper and his. On the one hand, he proves the generic existence of a complete market Ramsey allocation implementable through uncontingent bonds of different maturities. In addition, he shows that for the zero measure cases in which Ramsey cannot be implemented, it can be asymptotically approached in general, while we do it only for the case of two states. He also shows that, contrary to the general equilibrium

\footnotetext{
${ }^{8}$ The comments of a referee helped us to clarify these issues.

${ }^{9}$ Correia, Nicolini and Teles (2001) show that a similar argument holds in a model like the one of this paper with labor income taxes if we allow the goverenment to use state contingent consumption taxes.

${ }^{10}$ In fact, Marcet and Scott (2000) results suggest that the one bond economy imposes "too much" unit root behavior to the data. This suggests that more dimensions than just one period risk free bonds, but less than complete markets may do a better job in a positive excercise like theirs.
} 
literature, welfare is weakly increasing in the number of assets. On the other hand, as we do not restrict uncertainty to follow a Markov process, our examples shed additional light into the intuition behind the results on the optimal maturity structure. In particular, our discussion explains why it is difficult to obtain general results regarding the optimal maturity structure once we depart form the two-states-Markov example. In addition, our numerical section shows that the main policy implication of the theoretical result ought to be taken with care, since optimal positions are very high even in simple-smalldimensional problems and they change dramatically with small changes in the parameters of the model. Finally, we characterize a (zero measure) class of economies for which the Ramsey allocation cannot be implemented with non-contingent bonds independently of the number of maturities available.

The paper is organized in the following way. Section 2 presents the model and shows the main result of the paper. It also provides examples to illustrate how the maturity of the debt should be managed. In section 3 , we simulate the model to perform a quantitative exercise on the optimal debt structure. A final section concludes.

\section{The Economy}

We analyze the barter economy of Lucas and Stokey (1983). We model a one perishable good economy with production. The representative agent is endowed with one unit of labor in every period. Labor is the single factor of production, and the technology is given by

$$
c_{t}+g_{t} \leq s_{t}\left(1-x_{t}\right), \quad t=0,1,2, \ldots, \text { all } g^{t} .
$$

where $x_{t}, c_{t}$ and $g_{t}$ represent leisure and private and public consumption respectively, and $s_{t}$ is a productivity shock.

As it is standard in the Ramsey literature, government consumption is exogenous and follows some stochastic process. We assume $g_{t}$ and $s_{t}$ are the only source of uncertainty in this economy. We also assume that at each $t$, there is a finite number $N$ of possible values for the pair $h_{t}=\left(s_{t}, g_{t}\right)$. This assumption allows us to make the point of the paper in a very clean way. Let $h^{t}=\left\{h_{0}, \ldots, h_{t}\right\}$ be the history of shocks up to time $t$.

Preferences are represented by the following von Neumann-Morgenstern utility function 


$$
E_{0} \sum_{t=0}^{\infty} \beta^{t}\left[U\left(c_{t}\left(h^{t}\right), x_{t}\left(h^{t}\right)\right)\right]
$$

$\beta \in(0,1), U$ strictly increasing in both arguments and strictly concave.

The only tax available to the government is a flat rate tax $\tau_{t}$ levied on labor income. The government can also issue debt (that can be negative).

A complete markets Ramsey problem is to choose the allocation $\left\{c_{t}, x_{t}\right\}_{t=0}^{\infty}$ that maximizes utility subject to (1) and subject to the constraint that the allocation can be decentralized as a complete markets competitive equilibrium with income taxes. As it is standard in the literature, this last restriction can be represented by a single equation, the implementability constraint. This implementability constraint is obtained by replacing the complete markets competitive equilibrium prices in the life-time budget constraint of consumers ${ }^{11}$. If we let $U_{y, t}$ denote the partial derivative of the function $U$ with respect to the variable $y$ at time $t$, this implementability constraint becomes

$$
E_{0} \sum_{t=0}^{\infty} \beta^{t}\left[c_{t} \frac{U_{c, t}}{U_{c, 0}}-\left(1-x_{t}\right) \frac{U_{n, t}}{U_{c, 0}}\right]=b_{-1}
$$

where $b_{-1}$ represents the value of liabilities inherited by the government in units of time zero consumption.

We will consider two full commitment environments with different asset markets. In the first one, we let the government issue one period state contingent debt. Let $b_{t}\left(h^{t}, h_{t+1}\right)$ stand for the contingent debt issued by the government in period $t$, given history $h^{t}$, to pay one unit of the consumption good in period $t+1$ contingent on the shock $h_{t+1}$ being realized ${ }^{12}$. In the second, we let the government issue each period non-contingent bonds maturing at $J$ consecutive dates. Let $b_{t}^{j}\left(h^{t-1}\right)$ denote the time $t$, after history $h^{t-1}$, outstanding liabilities to deliver goods in period $t+j$ in any state of nature.

\footnotetext{
${ }^{11}$ For details, see Lucas and Stokey (1983) or an appendix to this paper available from the authors upon request.

${ }^{12}$ Note that we do not consider the case of contingent debt with different maturities. For the case with commitment there is no loss of generality by doing this.
} 


\subsection{The solution with state contingent bonds}

In this subsection we discuss the structure of the optimal debt when oneperiod state contingent bonds can be issued.

The first sequence of constraints of the Ramsey problem (1) ensures aggregate material balance for every period and every contingency. The second constraint (3) ensures that the resulting allocation can be implemented as a competitive equilibrium with complete markets. To be able to represent all these equilibrium conditions in a single equation, the assumption of complete markets is essential. Note that we could write a similar condition at time $t$

$$
z_{t-1}\left(h^{t-1}, h_{t}\right)=E_{t} \sum_{s=t}^{\infty} \beta^{t}\left[c_{s}\left(h^{s}\right) \frac{U^{\prime}\left(c_{s}\left(h^{s}\right)\right)}{U^{\prime}\left(c_{t}\left(h^{t}\right)\right)}-\left(1-x_{s}\left(h^{s}\right)\right) \frac{V^{\prime}\left(x_{s}\left(h^{s}\right)\right)}{U^{\prime}\left(c_{t}\left(h^{t}\right)\right)}\right]
$$

The right hand side of this equation is the expected discounted value of the government surplus from period $t$ (history $h^{t}$ ) on. That should be equal to the contingent liabilities the government has to honor at date $t$, given history $h^{t}$. In other words, for the government to be able to finance its deficits (surpluses) from date $t$ on, conditioned on history $h^{t}$, a certain amount of wealth (debt) must be delivered at $t$, conditioned on that history, which we denote as $z\left(h^{t-1}, h_{t}\right)$.

In a world with complete markets, we let $b_{t-1}\left(h^{t-1}, h_{t}\right)$ represent outstanding debt obligations at time $t$, given that state $h^{t}$ has realized, conditional on history $h^{t-1}$, so $b_{t-1}\left(h^{t-1}, h_{t}\right)=z_{t-1}\left(h^{t-1}, h_{t}\right)$.

Note that given a Ramsey allocation, the right hand side of this equation is determined. The requirement of complete markets is equivalent to imposing no constraint equalizing the values of $b_{t-1}\left(h^{t-1}, h_{t}\right)$ for alternative realizations of $h_{t}$, except for (3), that imposes a present value condition for all $t, h^{t}$. On the other hand, if we assume, as in Aiyagari et. al. (2002) that there are only uncontingent one-period bonds, the restriction that $b_{t-1}\left(h^{t-1}, h_{t}\right)=b_{t-1}\left(h^{t-1}\right)$ for all $h_{t}, h^{t-1}$ and $t \geq 0$, must be added to the Ramsey problem. Thus, one way of understanding the Ramsey problem with complete markets is that it allows the $b_{t-1}\left(h^{t-1}, h_{t}\right), t \geq 1$ be unconstrained $^{13}$. In this way, once the Ramsey problem with complete markets has been solved, one can disentangle the optimal one-period state contingent debt structure for every period and every state using equation (4).

\footnotetext{
${ }^{13}$ Of course, (3) implies that the sequence of $b_{t-1}\left(g^{t}, g_{t-1}\right)$ satisfies the relevant present value condition.
} 


\subsection{A rich maturity structure of non-contingent bonds}

In this section, we want to show how, if $J$ is large enough, a structure of debt maturities replicates a structure of state contingent bonds. Recall that $b_{t}^{j}\left(h^{t-1}\right)$ is the amount of promises held in period $t$ to pay a unit of consumption at time $t+j$. Let $p_{t}^{j}\left(h^{t-1}, h_{t}\right)$ be the price, in units of time $t$ goods, of a promise to deliver one unit of the good at time $t+j$, for $j=0,1, \ldots J$. Then, the time $t$ value of outstanding obligations, conditional on the realization $h_{t}$, are given by

$$
V\left(h^{t-1}, h_{t}\right)=\sum_{i=0}^{J-1} p_{t}^{i}\left(h^{t-1}, h_{t}\right) b_{t}^{i}\left(h^{t-1}\right)
$$

The main insight of the paper is based on the fact that although $b_{t}^{i}\left(h^{t-1}\right)$ cannot depend on the state of nature at time $t, V\left(h^{t-1}, h_{t}\right)$ does since it is a function of the prices $p_{t}^{i}\left(h^{t-1}, h_{t}\right)$, which do varies with the current shock. Thus, while the amount of debt issued at $t-1$ cannot depend on the state of nature at $t$, its time $t$ value in terms of current consumption does, and, therefore, the value of the debt obligations can be made contingent on the state of nature. Note that for this to be the case, it is essential to have debt of more than one period, since $p_{t}^{0}=1$.

Using equilibrium bond prices, the expression can also be written as

$$
V\left(h^{t-1}, h_{t}\right)=\sum_{i=0}^{J-1} \frac{E_{t}\left[\beta^{i} u^{\prime}\left(c_{t+i}\right) \mid h^{t-1}, h^{t}\right]}{u^{\prime}\left(c_{t}\right)} b_{t}^{i}\left(h^{t-1}\right)
$$

where $E_{t}\left[\beta^{i} u^{\prime}\left(c_{t+i}\right) \mid h^{t-1}, h^{t}\right]$ represents the time $t$ expected utility of $t+i$, conditioned on history $\left[h^{t-1}, h^{t}\right]$.

We are interested in finding conditions such that, by appropriately choosing the values of $b_{t}^{j}\left(h^{t-1}\right)$ for $j=0,1,2, \ldots, J-1$, the government can reproduce the required Ramsey values $z_{t-1}\left(h^{t-1}, h^{t}\right)$ for all $t,\left(h^{t-1}, h^{t}\right)$. Thus, it has to be the case that

$$
V\left(h^{t-1}, h_{t}\right)=\sum_{i=0}^{J-1} \frac{E_{t}\left[\beta^{i} u^{\prime}\left(c_{t+i}\right) \mid h^{t-1}, h^{t}\right]}{u^{\prime}\left(c_{t}\right)} b_{t}^{i}\left(h^{t-1}\right)=z\left(h^{t-1}, h_{t}\right)
$$

for all $h_{t}, h^{t-1}$, and $t \geq 0$. 


\subsubsection{Full rank condition}

Let the vector of government debt of different maturities be

$$
b_{t}\left(h^{t-1}\right)=\left(\begin{array}{l}
b_{t}^{0}\left(h^{t-1}\right) \\
b_{t}^{1}\left(h^{t-1}\right) \\
\cdots \\
b_{t}^{J-1}\left(h^{t-1}\right)
\end{array}\right),
$$

the matrix of returns of the debt in period $t$,

$$
A_{t}\left(h^{t}\right)=\left(\begin{array}{llll}
1 & \beta \frac{E_{t}\left[U^{\prime}\left(c_{t+1}\right) \mid h^{t-1}, h_{1}\right]}{U^{\prime}\left(c_{t}\right)} & \ldots & \beta^{J-1} \frac{E_{t}\left[U^{\prime}\left(c_{t+J-1}\right) \mid h^{t-1}, h_{1}\right]}{U^{\prime}\left(c_{t}\right)} \\
1 & \beta \frac{E_{t}\left[U^{\prime}\left(c_{t+1}\right) \mid h^{t-1}, h_{2}\right]}{U^{\prime}\left(c_{t}\right)} & \ldots & \beta^{J-1} \frac{E_{t}\left[U^{\prime}\left(c_{t+J-1}\right) \mid h^{t-1}, h_{2}\right]}{U^{\prime}\left(c_{t}\right)} \\
\vdots & \vdots & \ddots & \vdots \\
1 & \beta \frac{E_{t}\left[U^{\prime}\left(c_{t+1}\right) \mid h^{t-1}, h_{N}\right]}{U^{\prime}\left(c_{t}\right)} & \cdots & \beta^{J-1} \frac{E_{t}\left[U^{\prime}\left(c_{t+J-1}\right) \mid h^{t-1}, h_{N}\right]}{U^{\prime}\left(c_{t}\right)}
\end{array}\right)
$$

and the vector of wealth transfers

$$
Z_{t}\left(h^{t-1}\right)=\left(\begin{array}{l}
z_{t}\left(h^{t-1}, h_{1}\right) \\
z_{t}\left(h^{t-1}, h_{2}\right) \\
\cdots \\
z_{t}\left(h^{t-1}, h_{N}\right)
\end{array}\right)
$$

Then, the system of equations for period $t$, given history $h^{t-1}$ can be written as,

$$
A_{t}\left(h^{t}\right) b_{t-1}\left(h^{t-1}\right)=Z_{t}\left(h^{t-1}\right)
$$

If the matrix of returns $A_{t}\left(h^{t}\right)$ is nonsingular we obtain

$$
b_{t-1}\left(h^{t-1}\right)=A_{t}\left(h^{t}\right)^{-1} Z_{t}\left(h^{t-1}\right)
$$

which means that we can always find an intertemporal strategy of debt issues to support the Ramsey allocation.

A necessary condition for the Ramsey to be implementable is that the government can issue non-contingent bonds in at least as many maturities as possible realizations of the shock, i.e., $J \geq N$.

In the Ramsey allocation, the interest rate between period $t$ and $t+j$ depends both on the marginal utility in each state and on the conditional 
probability of each state. Thus, more stringent necessary conditions can be expressed as conditions on both the vector of marginal utilities and the transition probability matrix.

\subsubsection{The Markov case}

Assume that the shock follows a Markov chain with transition matrix $\Pi$. In this case, the matrix of returns can be written as $A_{t}\left(h^{t}\right)=D . B$, where

$$
D=\left(\begin{array}{llll}
\frac{1}{U^{\prime}\left(c\left(h_{1}\right)\right)} & 0 & \ldots & 0 \\
0 & \frac{1}{U^{\prime}\left(c\left(h_{2}\right)\right)} & \cdots & 0 \\
& & \cdots & \\
0 & & \cdots & \frac{1}{U^{\prime}\left(c\left(h_{N}\right)\right)}
\end{array}\right)
$$

and

$$
B=\left(\begin{array}{llll}
U^{\prime}\left(c_{1}\right) & \beta E\left[U^{\prime}\left(c\left(h_{t+1}\right) \mid h_{t}=h_{1}\right]\right. & \ldots & \beta^{J-1} E\left[U^{\prime}\left(c\left(h_{t+J-1}\right) \mid h_{t}=h_{1}\right]\right. \\
U^{\prime}\left(c_{2}\right) & \beta E\left[U^{\prime}\left(c\left(h_{t+1}\right) \mid h_{t}=h_{2}\right]\right. & \ldots & \beta^{J-1} E\left[U^{\prime}\left(c\left(h_{t+J-1}\right) \mid h_{t}=h_{2}\right]\right. \\
& \ldots & \\
U^{\prime}\left(c_{N}\right) & \beta E\left[U^{\prime}\left(c\left(h_{t+1}\right) \mid h_{t}=h_{N}\right]\right. & \ldots & \beta^{J-1} E\left[U^{\prime}\left(c\left(h_{t+J-1}\right) \mid h_{t}=h_{N}\right]\right.
\end{array}\right)
$$

Thus, as $\operatorname{rank}(D B)=\min \{\operatorname{rank}(D), \operatorname{rank}(B)\}$ and the diagonal matrix with nonzero elements of the diagonal is nonsingular, then $\operatorname{rank}(D B)=$ $\operatorname{rank}(B)$.

Using standard properties of Markov chains and letting the vector of marginal utilities for the $N$ different states be

$$
U c=\left(\begin{array}{l}
U^{\prime}\left(c\left(h_{1}\right)\right) \\
U^{\prime}\left(c\left(h_{2}\right)\right) \\
\cdots \\
U^{\prime}\left(c\left(h_{N}\right)\right)
\end{array}\right)
$$

the $j$ th column of the matrix $B$ can be written as

$$
\beta^{j-1} \Pi^{j-1} U c
$$

Then, the Ramsey allocation can be supported with bonds of $N$ different maturities if the vectors $\beta^{j-1} \Pi^{j-1} U c, j=1, \ldots, N$ are linearly independent. It is interesting to discuss the roles that $\Pi$ and $U c$ play. 
Less than full rank cases First, if the elements of $U c$ are equal, the interest rate does not depend on the state of nature. Then, all vectors in matrix $B$ are linearly dependent, and the rank is equal to one. In this case, the term structure of interest rates is flat for every state of nature ${ }^{14}$. Bonds of different maturities are the same asset so the economy behaves as in Aiyagari, Marcet, Sargent and Seppala (2002).

Second, if the shocks are i.i.d., then $\Pi^{j}=\Pi$ for all $j$. Thus, if there are more than two states, it is required that the shocks have some persistence. If the shocks are i.i.d., bonds of more than two periods are equivalent.

Finally, note that if the elements of $U c$ are not equal, and $\Pi$ is not i.i.d., then the vectors $\beta^{j-1} \Pi^{j-1} U c$ are linearly independent of each other. This is so, since $\Pi^{j} U c=\Pi\left(\Pi^{j-1} U c\right)$, and the matrix $\Pi$ is a probability matrix, so the maximum value of the vector $\Pi^{j-1} U c$ is higher than the maximum value of the vector $\Pi^{j} U c$. Similarly, the minimum value of the vector $\Pi^{j-1} U c$ is lower than the minimum value of the vector $\Pi^{j} U c$. Thus, there exists no real number such that one is the product of the other. But if $\Pi^{j-1} U c$ and $\Pi^{j} U c$ are linearly independent, so must be $\beta^{j-1} \Pi^{j-1} U c$ and $\beta^{j} \Pi^{j} U c$. Even though all columns are linearly independent, a combination of two of them can be linearly dependent of a third. In fact, it is possible to characterize a class of transition matrices that exhibit persistence but such that, for any preferences, the matrix of returns cannot be inverted. Indeed, let $\Pi$ be any i.i.d. matrix. Then, for any transition matrix defined as $\theta \Pi+(1-\theta) I^{15}$, where $\theta \in(0,1)$, the matrix of returns will be $\operatorname{singular}^{16}$.

Conditions for full rank The results discussed above can be used to characterize necessary and sufficient conditions for the matrix of returns to be nonsingular if we restrict the process to the case in which the transition matrix is Markov. If $N=2$, the matrix of returns will be nonsingular if and only if the elements of the vector of marginal utilities, $U c$, are not equal. However, if $N=3$, the "persistence" of the process and the condition over the vector of marginal utilities, $U c$, are necessary conditions, but not sufficient ${ }^{17}$.

\footnotetext{
${ }^{14} \mathrm{~A}$ utility funtion in which labor and consumption are separable and labor enters linearly would deliver this result.

${ }^{15}$ This is a popular class of transition matrices, since the degree of persistence is parameterized by the scalar $\theta$.

${ }^{16}$ The proof is available from the authors upon request.

${ }^{17}$ Angeletos (2002) proves that generically, the complete markets second best allocation can be implemented with $J \geq M$ maturities, so these cases represent a set of measure
} 


\subsection{Examples}

We next present two examples in which $J=N=2$ to give the main intuition of the problem. We assume that there are no productivity shocks $\left(s_{t}=1\right.$ for all $t$ ) and that government expenditures can take only two possible values. Thus, for this particular case, $h_{t}=g_{t}$.

In the first example, uncertainty evolves according to a Markov chain. In this case, it is possible to show that the optimal maturity structure is to hold long term debt and short run assets. In the second example, uncertainty is not characterized by a Markov chain, and is selected to highlight the intuition of the Markov case.

We first need to emphasize a property of the Ramsey solution. As it should be clear from last section, a key element to determine the optimal debt structure is the behavior of the yield curve associated with the Ramsey allocation. This will be given by the holding return of the different bonds, which in turn depends on the correlation between consumption and government expenditures. It is hard to obtain results regarding this correlation without restricting preferences. The reason being that an increase in government expenditures has a negative income effect on private consumption through the constraint (1). On the other hand, the optimal tax rate will respond to this increase in government expenditures. If the optimal response is to lower the income tax rate, then there will be a positive substitution effect on private consumption. It turns out that it is easy to characterize preferences such that private consumption will be negatively correlated with government spending ${ }^{18}$. For the rest of the paper, we assume this is indeed the case to illustrate the properties of optimal debt management. From the discussion it will become clear how results would differ if consumption and government expenditures were positively correlated.

In addition, it is a well known property of the Ramsey solution that the allocation satisfies $c_{t}\left(g_{t}, \lambda\right), x_{t}\left(g_{t}, \lambda\right)$, were $\lambda$ is the multiplier of the implementability constraint. Thus, when the shock follows a Markov chain, the

zero.

${ }^{18}$ In the working paper version we show that $U(c, x)=u(c)-v(1-x)$, and $v^{\prime \prime \prime}$ are sufficient conditions for $c$ and $g$ to be negatively correlated. 
vector $Z_{t}\left(g^{t-1}\right)$ is independent of $g^{t-1}$. In addition,

$$
A_{t}\left(g^{t}\right)=\left(\begin{array}{llll}
\frac{1}{U^{\prime}\left(c\left(g_{1}\right)\right)} & 0 & \ldots & 0 \\
0 & \frac{1}{U^{\prime}\left(c\left(g_{2}\right)\right)} & \cdots & 0 \\
\vdots & \vdots & \ddots & \vdots \\
0 & 0 & \cdots & \frac{1}{U^{\prime}\left(c\left(g_{N}\right)\right)}
\end{array}\right) B
$$

and the columns of the matrix $B$ are given by $\beta^{j-1} \Pi^{j-1} U c$, so $B$ is independent of the state ${ }^{19}$. Therefore, as both $A_{t}\left(g^{t-1}\right)$ and $Z_{t}\left(g^{t-1}\right)$ are independent of the history, the optimal maturity structure is invariant with respect to the time period and the state. For this Markov case, then, we let $Z_{t}\left(g^{t-1}\right)=Z, A_{t}\left(g^{t-1}\right)=A$ and $b_{t-1}\left(h^{t-1}\right)=b$

Example 1 Let $b_{0}^{j}=0, j=1,2 ; g_{0}=g_{h}$ and assume that government expenditure follows a Markov process with two states, $g_{h}>0$ and $g_{l}=0$, with transition matrix $\Pi=\left(\begin{array}{ll}\pi_{h h} & \pi_{h l} \\ \pi_{l h} & \pi_{l l}\end{array}\right)$.

In this two state case,

$$
Z=\left(\begin{array}{c}
z\left(g_{h}\right) \\
z\left(g_{l}\right)
\end{array}\right)
$$

and it is a straightforward exercise to show that $z\left(g_{h}\right)=0$, and that $z\left(g_{l}\right)>0$. The intuition is simple. Periods with a high expenditure shock are identical to the initial period, so the value of future surpluses is zero, as in the first period. As the government will issue debt that pays when government expenditures are low, those periods must therefore be characterized by positive values of future surpluses.

The optimal maturity structure satisfies

$$
\left(\begin{array}{cc}
1 & \beta E_{h} \frac{U^{\prime}(c)}{U^{\prime}\left(c_{h}\right)} \\
1 & \beta E_{l} \frac{U^{\prime}(c)}{U^{\prime}\left(c_{l}\right)}
\end{array}\right)\left(\begin{array}{l}
b^{1} \\
b^{2}
\end{array}\right)=\left(\begin{array}{l}
0 \\
z_{l}
\end{array}\right)
$$

\footnotetext{
${ }^{19}$ If the shock were a second order autoregresive process for instance, then both the vector of expected future surpluses and the matrix $B$ would depend on the history and so will the optimal maturity structure. As a referee pointed out, however, one can always write any finite order autoregressive process as a first order Markov process by redifining (enlarging) the state space such that there is always a time invariant optimal maturity structure, involving more maturities than N. See Angeletos (1999) for details.
} 
were $b^{j}$ indicates debt that matures in $j$ periods and $E_{h} U^{\prime}(c), E_{l} U^{\prime}(c)$ are the expected marginal utility conditional on $g_{t}=g_{h}$ and $g_{t}=g_{l}$ respectively. The determinant of the system is given by

$$
\operatorname{det}=\frac{\beta}{U^{\prime}\left(c_{h}\right) U^{\prime}\left(c_{l}\right)}\left[U^{\prime}\left(c_{h}\right) E_{l} U^{\prime}(c)-U^{\prime}\left(c_{l}\right) E_{h} U^{\prime}(c)\right]
$$

By definition, $E_{l} U^{\prime}(c)$ and $E_{h} U^{\prime}(c)$ are weighted averages of $U^{\prime}\left(c_{h}\right)$ and $U^{\prime}\left(c_{l}\right)$. Thus, as long as the transition matrix is not the identity matrix (in which case there is no uncertainty), and $U^{\prime}\left(c_{h}\right)>U^{\prime}\left(c_{l}\right)^{20}, U^{\prime}\left(c_{h}\right) \geq$ $E_{h} U^{\prime}(c)$, and $E_{l} U^{\prime}(c) \geq U^{\prime}\left(c_{l}\right)$, with strict inequality for at least one of them. Then $U^{\prime}\left(c_{h}\right) E_{l} U^{\prime}(c)>E_{h} U^{\prime}(c) U^{\prime}\left(c_{l}\right)$ and the determinant is nonzero. Thus, $U^{\prime}\left(c_{h}\right) \neq U^{\prime}\left(c_{l}\right)$ is the necessary and sufficient condition for the matrix of returns to be nonsingular.

Note also, that in the particular case in which $U^{\prime}\left(c_{h}\right)=U^{\prime}\left(c_{l}\right)$ at the Ramsey solution, the government can slightly reduce the tax in the case in which expenditure is zero and increase it in the case in which expenditure is positive in order to satisfy the government budget constraint. With consumption monotonically decreasing with taxes, we obtain $U^{\prime}\left(c_{h}\right)>U^{\prime}\left(c_{l}\right)$ such that the matrix of returns is nonsingular. Thus, by making the tax perturbation small enough, welfare can be made arbitrarily close to the Ramsey solution $^{21}$.

Thus, if $U^{\prime}\left(c_{h}\right) \neq U^{\prime}\left(c_{l}\right)$, the solution for the optimal maturity structure is therefore given by

$$
\left(\begin{array}{l}
b^{1} \\
b^{2}
\end{array}\right)=\left(\begin{array}{l}
\frac{-U^{\prime}\left(c_{l}\right) E_{h} U^{\prime}(c) z_{l}}{\operatorname{det}} \\
\frac{z_{l}}{\operatorname{det}}
\end{array}\right)
$$

This is a particular case of (5). As $z_{l}>0$, then $b^{1}<0$ and $b^{2}>0$.

The optimal structure involves holding short run assets and long run liabilities. The intuition is simple: the interest rate goes up when government expenditures go up, so long term debt prices fall relative to short term debt. At the same time, the government needs resources when government expenditures go up. The way to accrue them is to hold short run assets and long term liabilities whose value is lower when government expenditures go up.

\footnotetext{
${ }^{20}$ Note that a similar argument can be used to show that the determinant is nonzero in the case in which $U^{\prime}\left(c_{h}\right)>U^{\prime}\left(c_{l}\right)$. Thus, the condition $U^{\prime}\left(c_{h}\right) \neq U^{\prime}\left(c_{l}\right)$ is in fact sufficient.

${ }^{21}$ Angeletos (1999) proves this result for any value of $N$. Incidentally, note that while welfare approaches the Ramsey value, the size of the positions goes to infinity, since the value of the determinant goes to zero.
} 
This result holds for general Markov transition matrices. The reason is straightforward. There are three main ingredients in the result. First, consumption is reduced when government expenditures go up. Second, the Markov structure implies reversion to the mean in terms of future expected consumption. Finally, the government runs a deficit when government expenditures are high and a surplus when government expenditures are low. The first two components imply that the term structure of interest rates is decreasing when government expenditures are high and increasing when government expenditures are low. Thus, short term debt becomes relatively expensive when government expenditures are low and cheaper when government expenditures are high. The third component explains, given the behavior of relative prices, the optimal debt structure.

The preceding example is, of course, not a general result. One can construct examples, somewhat convoluted, where the optimal debt structure is the opposite. All we need, for instance, is an upward sloping term structure when government expenditures are high.

Example 2 (Escalating War) Let $b_{0}^{j}=0, j=1,2$; let $g_{t}=0$ for all $t \neq T$ and let $g_{T}=G_{1}>0$ with probability $\alpha$ and $g_{T}=0$ with probability $1-\alpha$. For $t>T, g_{t}=G_{2}>G_{1}$ if $g_{T}=G_{1}$ and $g_{t}=0$ if $g_{T}=0$.

Define $\omega_{G_{1}}=\omega\left(g=G_{1}\right), \omega_{G_{2}}=\omega\left(g=G_{2}\right)$ and $\omega_{0}=\omega(g=0)$ (same interpretation for the other variables). To see how the government implements the Ramsey allocation using non-contingent debt with two maturities we look at the implementability constraints of period $T$ in both states,

$$
\begin{aligned}
b_{T-1}^{1}+\beta \frac{U_{G_{2}}^{\prime}}{U_{G_{1}}^{\prime}} b_{T-1}^{2} & =\omega_{G_{1}}+\frac{\beta}{1-\beta} \omega_{G_{2}} \\
b_{T-1}^{1}+\beta b_{T-1}^{2} & =\omega_{0}+\frac{\beta}{1-\beta} \omega_{0}
\end{aligned}
$$

We can write the system as

$$
\left(\begin{array}{ll}
1 & \frac{U_{G_{2}}^{\prime}}{U_{G_{1}}^{\prime}} \\
1 & 1
\end{array}\right)\left(\begin{array}{l}
b_{T-1}^{1} \\
b_{T-1}^{2}
\end{array}\right)=\left(\begin{array}{l}
\omega_{G_{1}}+\frac{\beta}{1-\beta} \omega_{G_{2}} \\
\omega_{0}+\frac{\beta}{1-\beta} \omega_{0}
\end{array}\right)
$$

so the solution for the values of debt issued at $T-1$ is 


$$
\begin{aligned}
b_{T-1}^{1} & =\frac{U_{0}^{\prime}\left[\omega_{G_{1}}+\frac{\beta}{1-\beta} \omega_{G_{2}}\right]-U_{G_{2}}^{\prime} \frac{\omega_{0}}{1-\beta}}{\beta U_{0}^{\prime}\left(U_{G_{1}}^{\prime}-U_{G_{2}}^{\prime}\right)} \\
b_{T-1}^{2} & =\frac{-U_{0}^{\prime}\left[\omega_{G_{1}}+\frac{\beta}{1-\beta} \omega_{G_{2}}\right]+U_{G_{1}}^{\prime} \frac{\omega_{0}}{1-\beta}}{\beta U_{0}^{\prime}\left(U_{G_{1}}^{\prime}-U_{G_{2}}^{\prime}\right)}
\end{aligned}
$$

It is straightforward to show that $\omega_{0}>0$ and $\omega_{G_{1}}+\frac{\beta}{1-\beta} \omega_{G_{2}}<0$. As $U_{G_{2}}^{\prime}>$ $U_{G_{1}}^{\prime}, b_{T-1}^{1}>0$ and $b_{T-1}^{2}<0$. Thus, contrary to the previous example, the government issues short term debt and buys assets that mature in the long run.

The intuition again is very simple. What matters for the maturity structure that implements the Ramsey allocation is the behavior of the interest rate in the different states of nature. In this example, expenditure being high at period $T$ is associated with a scarcity of goods in $T+1$ relative to period $T$ (since the expenditure will be even higher). While if the expenditure turns out to be low at $T$, it will be constant from then on. So, the price of a good tomorrow, conditional on the expenditure being high, is lower (i.e., the interest rate is lower when the expenditure is high, relative to the case in which it is low). The basic difference is that we don't have "mean-reversion" of expenditures in this case, a feature that Markov chains do exhibit.

These two state cases highlight the intuition of the result. However, in order to obtain further insights, like studying the interactions of the two sources of uncertainty we considered in Section 2.2, we need to go beyond the two state case. Do these results just discussed generalize to cases in which $N>2$ ? Once we increase the number of states, it is unclear either how the additional terms of the term structures will behave, or whether a surplus or a deficit will be run in each particular states. Thus, the features of the optimal debt structure may well be dependent on parameter values. The results of the simulations we present in the next section suggest this is exactly the case.

\section{Simulations}

In this section we compute the optimal debt maturities implied by a Ramsey model calibrated to US data. We first solve a simple two state case with only expenditure shocks and then move to consider shocks to both expenditures 
and productivity. We then explore how robust the results are to variations on the parameters and on the number of states.

\subsection{Two states}

We first present a two states case aimed at capturing big expenditure shocks, such as wars. The transition matrix is such that a war occurs twice a century with an average duration of 3 years. During the peace, state government expenditure represents $26 \%$ of $\mathrm{GDP}^{22}$ while in the war state it reaches $56 \%$. The functional form for preferences and the parameter values are as in Aiyagari, Marcet, Sargent and Seppala (2002). The details of the calibration and computation are reported in the appendix.

Table 1.A presents the value of optimal debt positions ${ }^{23}$ as a fraction of peace-time GDP. For each maturity $j$, the numbers indicate the value ${ }^{24}$ in units of current consumption when expenditures are low of a promise to deliver $b^{j}$ goods at time $t+j$. We report results both for quarterly and yearly calibrations. The main reason for reporting the two cases is that the calibrated persistence of the expenditure shock is lower at a yearly frequency. We argued in the examples of the previous section that this parameter matters for the determination of the optimal debt positions so we want to explore its quantitative implications. We also report the yearly returns on short period bonds: for the quarterly calibration, it corresponds to a 90 days bond, while for the yearly calibration it corresponds to a one year bond. In both cases we report the sensitivity of the positions with respect to the risk aversion parameter.

The size of each financial transaction for every period ranges from 1.5 to 20 times peace-times GDP. These numbers are very high, relative to actual magnitudes. As expected, debt positions get smaller with higher curvature parameters because the variations on interest rates are higher, although for reasonable values positions are still large. In addition, positions get lower as

\footnotetext{
${ }^{22}$ The values for government expenditure during a war is set to match the increase in government expenditure observed in the WWI and WWII for the US. The increase relative to peace times was in the order of $30 \%$ of the GDP in both cases.

${ }^{23}$ We choose the maturities so as to minimize the present value of the absolute value of the positions and considered combination of maturities from 1 quarter to 30 years.

${ }^{24}$ In these models with Markov uncertainty and discounting, the price of time $t$ consumption in terms of $t+j$ consumption is increasing on $j$. To isolate the effect of that price on our results, we decided to report the value of the position in terms of current consumption.
} 
the calibration period is increased. The first reason is that lower persistence in expenditure shocks imply larger movements on interest rates. Note, however, that the quantitative impact on interest rates is very small. The second reason is that the lower the persistence, the lower the effect on the permanent wealth of the government, and, therefore, the lower the wealth transfers it needs to make at the optimum. This is the effect that really matters in this example.

Positions may also get smaller if we consider smaller shocks, since in that case there will be less need to transfer resources form one state to the other $^{25}$. Table 1.B shows the debt positions of an economy subject only to government spending shocks that correspond to magnitudes of the business cycle fluctuations of government spending. The transition matrix in this case is estimated using US data for government consumption during the postwar period. We report results for a quarterly calibration. The details and results of the estimation procedure are reported in the appendix. As we can see, the positions and interest rate fluctuations are more reasonable in this case, especially for high values of the curvature.

\subsection{Productivity shocks and $\mathrm{N}>2$}

Next, we simulate a model with 4 possible values for the state, two states for government expenditures and two states for the labor productivity. We used post-war US data to estimate the transition matrix of the processes; details and estimation results are reported in the appendix. Table 2.A presents the optimal maturity structure for several values of the curvature. As before, the numbers are in units of GDP in the "best" state, i.e., low expenditure and high productivity. The debt positions are huge, even though the maturities were chosen to minimize the sum of their absolute values. As a first robustness check, we also report the calibration corresponding to Chari et.al. $(1995)^{26}$. It is interesting that both models imply huge positions, in spite of having very different implications regarding interest rates movements.

\footnotetext{
${ }^{25}$ There is another effect that goes in the other direction. With smaller shocks, consumption may be less volatile, so the term structure will be less sensitive to the shocks. Thus, although we now need to transfer less resources across states, the movements in interest rates will also be smaller. However, if there is enough tax smoothing to start with, this second effect is overcomed by the first. This is borne out in our simulations.

${ }^{26}$ The details of this calibration are also reported in the appendix.
} 


\subsection{Varying the degree of persistence}

In our first simulation, we considered lowering the frequency of the calibration exercise. This naturally lead to a lower persistence parameter for the government shock, which in turn meant higher movements on the term structure (although of an irrelevant magnitude) and lower required wealth transfers. To obtain further insights, we consider now lowering the persistence of the Markov matrix for base-line cases of the two-states and four-states economies.

Table 3 report these exercises. We define the Markov matrix $M(\rho)=$ $\rho M+(1-\rho) I I D$ were $I I D$ is an i.i.d. matrix and $M$ is the calibrated matrix. Thus, the lower $\rho$, the lower the degree of persistence. As before, each positions is reported in units of current consumption and as a fraction of the GDP in the "best" case (low expenditure shock, high productivity shock).

For the two states case we confirm the intuition that the less persistent the shocks, the smaller the positions that implement a particular Ramsey allocation. Incidentally, note that for low values of $\rho$ we obtain uncomfortable variations on the interest rates. The effect of the persistence of the shocks on the 4 states examples is less clear. As we expected, the volatility of the interest rate is higher, but at the same time we obtain more correlated movements on the whole term structure. The overall effect is that the less persistent the shocks, at least in some range, the bigger the required positions.

The effect of more persistence on one period interest rate is all we need to know for the two sates case. However, with more than two states the auto-correlation matrix of the whole term structure matters and it is hard to obtain general results regarding the way it responds to different degrees of persistence. As it was the case in the theoretical examples, things become much more complicated with more than two states.

\subsection{Intuition of the results}

The fact that increasing the number of states is associated with more extreme debt positions is somewhat intuitive. Recall that to span more dimensions, we need to use independent movements in the term spreads. On the other hand, the higher the correlation between two assets, the smaller the determinant of the matrix of returns and the higher the positions. With Markov chains and for long maturities, the term spread is highly correlated (but clearly not perfectly correlated!) across maturities, since there is reversion to the mean. 
In the limit, given an ergodic transition matrix, the prices of bonds with different but very long maturities will be perfectly correlated. Thus, as the number of states goes to infinity, all term spreads must be used, and the absolute value of the positions also goes to infinity. At a first sight, appears remarkable $^{27}$ the rate at which positions increased with the introduction of new states. The analysis of the next section will further clarify this point.

\subsection{Robustness Analysis}

The simulations reported suggest two main results. First, that debt positions are extreme even for the simple four state case we studied. Second, they become larger as we increase the number of states. In this section, we report simulations that show these results to be robust.

To study the robustness of the first result, we hold all parameter values fixed and vary randomly, in a neighborhood, the transition matrix ${ }^{28}$. We perturbed each linearly independent element of the transition matrix estimated using US data (the base case corresponding to the second example of Table 2 with risk aversion of 1 ) with a random variable distributed as a $N(0, \sigma)$ and did the exercise for $\sigma$ equal to 0.10 and 0.01 . In each case we drew 100 realizations.

We report the frequency distribution of debt positions for the four maturities (one year, four years, thirteen years and thirty years) ${ }^{29}$. Figure 1 reports the results for $\sigma$ equal to 0.10 . Note that between $30 \%$ and $40 \%$ of the times, the absolute value of positions for one and four years maturities are higher than 100 times GNP, while for the thirteen and thirty years maturities, it is between $80 \%$ and $90 \%$ of the times. Note also that for these perturbations whether one should go short or long in a single positions is also highly volatile.

Figure 2 shows the results for $\sigma$ equal to 0.01 . In this case, the positions are higher on average and skewed toward higher maturities. It is interesting that even for these very small perturbations (95\% of the matrices we draw belong to a box of size 0.04 in the unit simplex), positions vary a lot, al-

\footnotetext{
${ }^{27}$ Less remarkable though, if we recall the results of the empirical literature on the term structure discussed in the introduction.

${ }^{28}$ While performing this exercise we are not exposed to the risk of moving through a pathological dimension.

${ }^{29}$ These positions minimize the present value of the absolute value of debt positions for the base case.
} 
though they do not change sign. As an example, bond positions for four year maturities range between 50 and more than 150 times GNP.

These results suggest that the problem of the size of the positions is not specific to the particular case we estimated in our baseline case, at least for the four state example. In addition, they show that the optimal debt structure is extremely sensitive to very small (in the order of less than 0.01 , on average, changes in the probabilities of the transition matrix) perturbations in the parameters.

To conclude, we report an exercise to understand the effect of increasing the number of states. We argued at the end of the previous section that with a Markov structure the returns tend to be very highly correlated for long positions. Thus, as more long positions are required to complete markets, the absolute size of the positions increases.

To consider this issue we considered government expenditure shocks only. We held constant all parameter values as in the yearly calibration of Table 1 A with risk aversion of 2 , including the support of the distribution of the shock. Then, for the case of two sates, we drew 100 Markov matrices using a uniform distribution on the set of all Markov matrices and computed the optimal debt positions. To replicate the procedure for $N$ possible values for the shock, we constructed a grid of $N$ equidistant points in the same support and drew 100 Markov matrices using a uniform distribution on the set of all $N$ dimensional Markov matrices. We carried out the exercise for $N=4,6$ and 8.

Figure 4 reports histograms of the present value of the absolute value of debt positions for the four cases. In all of them, the present value is divided by the dimension of the problem, so they should be interpreted as the present value normalized by the number of different maturities held. As it is clear from the graph, the numbers dramatically increase as we consider six and eight possible values for the shock ${ }^{30}$.

\footnotetext{
${ }^{30}$ In this exercise we are refining the grid for a given shock instead of considering other shocks. As a referee correctly mentioned the magnitudes of the positions increase less dramatically in the former case. Still, when we are considering 8 states of the world the magnitude of the positions are very high.
} 


\section{Conclusions}

In this paper, we show how a properly managed maturity structure of the debt allows a Ramsey government to implement the second best allocation in the absence of state contingent debt. The key intuition for the result is that as long as the term structure of interest rates depends on the shock, so does the relative price of non-contingent bonds of different maturities. Therefore, their returns are not perfectly colinear and span more states than a single asset does. Thus, if the number of maturities is the same as the possible states of nature, the complete market allocation can be implemented in general.

The theoretical results also show that the optimal maturity structure depends critically on the relationship between the term structure of interest rates and the realization of the shocks in ways that make general results hard to obtain, except for the case of two states Markov processes. We compute simple calibrated versions of the model to get a flavor of the policy implications of these results.

The general lesson from these simulations is that the size of financial transactions the government must undertake each period to replicate state contingent bonds is very large and increases dramatically with the number of states. In particular, when we calibrate to the US economy a simple four state process, the government is required to swap bonds of different maturities on the order of a few hundred times total GDP each period. In addition, the optimal maturity structure is sensitive to rather small changes in the parameters of the model.

The results of this paper suggest that exploring the optimal maturity of the debt in costly financial markets, or in environments where debt positions satisfy certain simple restrictions, like in Aiyagari, Marcet, Sargent and Seppala (2002) deserves attention in further analysis.

\section{Appendix}

In this appendix we describe the parametric form and parameters chosen for the different simulations. As our benchmark case we consider the following specification for preferences used by Aiyagari et. al. (2002) ${ }^{3132}$,

$$
u\left(c_{t}, x_{t}\right)=\frac{c_{t}^{1-\sigma_{1}}}{1-\sigma_{1}}+\eta \frac{x_{t}^{1-\sigma_{2}}}{1-\sigma_{2}}
$$

\footnotetext{
${ }^{31}$ This is the specification used for the quarterly and yearly calibration in table 1.A, the quarterly calibration on table 1.B and 2.A, and the exercises on figure 1,2 and 3

${ }^{32} \mathrm{We}$ also showed results using a yearly time period. We followed the parametrization
} 
The technology is a scaled-up version of the one considered in the section 2 ,

$$
c_{t}+g_{t}=s_{t}\left(100-x_{t}\right)
$$

where $s_{t}$ represent the productivity in moment $t$.

Except for the parameters of the stochastic processes and the discount factor, we used the parametrization in Aiyagari et. al. (2002) as our baseline case: $\left(\beta, \sigma_{1}, \sigma_{2}, \eta\right)=(.9875, .5,2,1)$. The value of the discount factor corresponds to the one used in Cooley (1995) to match the average quarterly interest rate.

In the case of the war-peace example (see table 1.A), the transition matrix and the value of the shocks were calibrated to fit in a broad sense the US experience over the previous century. We consider a war to be an episode that occurs, on average, twice a century with an average life of three years. The implied values for the transition probabilities are $\pi_{\text {peace, war }}=0.995$ and $\pi_{w a r, w a r}=0.917$. The value of the expenditures during peace time was set to 10 and its value during war time was set to be 20 (this is consistent with the US experience, during WWI and WWII government expenditures increased by about 0.3 times the GDP relative to its immediate peace time value).

The stochastic process for the quarterly business cycle example (see tables 1.B and 2.A, quarterly calibration) was estimated using HP filtered postwar US data on federal government expenditure and the Solow residual. We fitted two independent two-state Markov processes for $g_{t}$ and $s_{t}, g_{t}=\bar{g}+z_{g}$ and $s_{t}=\bar{s}+z_{s}\left(z_{g} \in\left\{z_{g_{l o w}}, z_{g_{\text {high }}}\right\}\right.$ and $\left.z_{s} \in\left\{z_{s_{\text {low }}}, z_{s_{\text {high }}}\right\}\right)$. We choose $\bar{g}=10$ and $\bar{s}=1$ and estimated $z_{g}$ and $z_{s}$ using the procedure described in Ravn and Sola (1995).

The estimates for the transition matrix of the government expenditure shocks are $\pi_{\text {low,low }}^{g}=0.837$ and $\pi_{\text {high,high }}^{g}=0.936$, and the ones for the in Chari et.al. (1995):

$$
\begin{gathered}
u(c, x)=\frac{\left[c^{1-\gamma} x^{\gamma}\right]^{\psi}}{\psi}, \\
F(l, z)=\left(e^{z}(1-x)\right)^{1-\alpha} .
\end{gathered}
$$

They used the following parameter values

$$
(\beta, \psi, \gamma, \alpha)=(.98,0, .75, .34)
$$

This specification and parameters values were used in for the year calibration of table 1.B, 2.A and 3.B. 
productivity shocks are $\pi_{\text {low }, \text { low }}^{s}=0.812$ and $\pi_{\text {high,high }}^{s}=0.919$. The estimates for state dependent means are $z_{g_{l o w}}=-1.822, z_{g_{\text {high }}}=0.5964, z_{s_{\text {low }}}=-1.05$ and $z_{s_{h i g h}}=0.3849$ (these are in percentage deviation from the mean $)^{33}$.

\footnotetext{
${ }^{33}$ The corresponding values for the table 1.B and 2.A, yearly calibration (Chari et. al. (1995) parameterization) are

$$
\left(\pi^{g}, \pi^{s}, z_{g_{h i g h}}, z_{s_{\text {high }}}\right)=(.95, .91, .08,1.04) .
$$

$z_{g_{l o w}}=-z_{g_{\text {high }}}, z_{s_{\text {low }}}=-z_{s_{\text {high }}}$. Both process follows a symmetric two-state Markov chain.
} 


\section{References}

[1] Aiyagari, S.R., Marcet, A., Sargent, T., Seppala, J., 2002. Optimal taxation without state-contingent debt, Journal of Political Economy 110, 1220-1254.

[2] Angeletos, G.M., 2002. Fiscal Policy with Non-contingent Debt and the Optimal Maturity Structure, Quarterly Journal of Economics 117, 11051131.

[3] Barro, R., 1979. On the Determination of Public Debt, Journal of Political Economy 87, 940-971.

[4] Bohn, H., 1990. Tax Smoothing with Financial Instruments, American Economic Review 80, 1217-1230.

[5] Chari, V., Christiano, L., Kehoe, P., 1995. Policy Analysis in Business Cycle Models, in: Cooley T. editor, Frontiers of Business Cycle Research (Princeton University Press).

[6] Chari, V., Kehoe, P., 1999. Optimal Fiscal and Monetary Policy, NBER working paper 6891.

[7] Chari, V., Kehoe, P., 1993. Sustainable Plans and Mutual Default, Review of Economics Studies 60, 175-195.

[8] Cochrane, J., 2001. Asset Pricing (Princeton University Press).

[9] Correia, I., Nicolini, J., Teles, P., 2001. Optimal Fiscal and Monetary Policy: Results on Tax Smoothing, mimeo, Universidad Di Tella.

[10] Litterman. R., Scheinkman, J., 1991. Common factors affecting bond returns, The Journal of Fixed Income 1, 54-61.

[11] Lucas, R., Stokey, N., 1983. Optimal fiscal and monetary policy in an economy without capital, Journal of Monetary Economics 12, 55-93.

[12] Marcet, A, Scott, A., 2000. Debt fluctuations and the Structure of Bond Markets, mimeo, Universitat Pompeu Fabra.

[13] Ravn, M. O., Sola, M., 1995. Stylized facts and regime changes: Are prices procyclical?, Journal of Monetary Economics 36, 497-526. 
Table 1

Debt Positions in Units of Peace-Time GDP and Interest Rates

Risk

Aversion Debt Positions $\left(\frac{p^{j}\left(g_{\text {low }}\right) b^{j}}{y\left(g_{\text {low }}\right)}\right)$

Short Term Interest Rates (\%)

\begin{tabular}{|c|c|c|c|c|}
\hline & $g_{\text {low }}$ & $g_{h i g h}$ \\
\hline \multicolumn{5}{|c|}{$\begin{array}{l}\text { A. War Example } \\
\text { Quarterly Calibration }\end{array}$} \\
\hline & $\mathrm{j}=0.25$ & $\mathrm{j}=30$ & & \\
\hline 0.50 & -18.20 & 19.33 & 1.88 & 3.96 \\
\hline 2.00 & -7.10 & 9.09 & 1.44 & 9.38 \\
\hline 10.00 & -5.56 & 7.22 & 1.40 & 9.77 \\
\hline \multicolumn{5}{|c|}{ Yearly Calibration } \\
\hline & $j=1$ & $\mathrm{j}=30$ & & \\
\hline 0.50 & -4.53 & 4.81 & 1.90 & 4.00 \\
\hline 2.00 & -1.77 & 2.26 & 1.46 & 9.64 \\
\hline 10.00 & -1.38 & 1.80 & 1.42 & 10.06 \\
\hline
\end{tabular}

B. Business Cycle

Quarterly Calibration

0.50

2.00

10.00

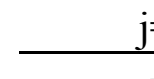

$\mathrm{j}=0.25$

$-2.88$

$-2.50$ $\mathrm{j}=30$

2.90

2.52
1.91

1.64

1.61
2.04

2.15

2.16

Note: In columns 2 and 3 we report the maturities implementing the Ramsey allocation that minimized the present value of the absolute value of the positions. In the war example the process for the government expenditures was calibrate to match the US experience during the 20th century (see the appendix for details). The business cycle examples were calibrated to match the US postwar experience. By quarterly (yearly) calibration we mean that the calibration and the simulation were done using a quarter (year) as our time period. In the quarterly (yearly) calibration the short-term interest rate correspond to the yearly return of a 3-month (1-year) bond. 
Table 2

Debt Positions and Interest Rates for the Four States Examples

Risk

Aversion

Debt Positions $\left(\frac{p^{j}\left(g_{\text {low }}, s_{\text {high }}\right) b^{j}}{y_{g_{\text {low }} s_{\text {high }}}}\right)$

Short Term Interest Rates (\%)

$g_{\text {low }}, S_{\text {high }} g_{\text {low }}, s_{\text {low }} \quad g_{\text {high }}, S_{\text {high }} \quad g_{\text {high }}, s_{\text {low }}$

Business Cycle Examples

Our Calibration

$\begin{array}{lcccccccc} & \mathrm{J}=0.25 & \mathrm{j}=1 & \mathrm{j}=2 & \mathrm{j}=30 & & & & \\ 0.50 & -21.83 & 146.08 & 322.70 & 198.46 & 1.03 & 3.93 & 1.15 & 4.06 \\ 2.00 & -10.10 & 65.61 & -140.41 & 84.92 & -1.15 & 7.68 & -0.66 & 8.21 \\ 10.00 & -9.13 & 60.22 & -129.22 & 78.13 & -0.44 & 6.16 & 0.07 & 6.73\end{array}$

Calibration of Chari et. al. (1995)

$\begin{array}{lcccccccc} & \mathrm{J}=1 & \mathrm{j}=4 & \mathrm{j}=13 & \mathrm{j}=30 & & & & \\ 1.00 & -24.62 & 71.96 & -171.89 & 125.12 & 1.81 & 2.04 & 1.99 & 2.23 \\ 2.00 & -13.58 & 45.01 & -125.93 & 95.07 & 0.93 & 2.08 & 1.90 & 3.12 \\ 9.00 & -7.49 & 20.52 & -43.39 & 30.00 & 0.41 & 2.58 & 1.25 & 3.54\end{array}$

Note: In columns 2 to5 we report the maturities implementing the Ramsey allocation that minimized the average value of the absolute value of the positions. The business cycle examples were calibrated to match the US postwar experience. Our calibration was done taking a quarter as the time period, while Chari et. al. (1995) use the year. In our (Chari et. al. (1995)) calibration the short-term interest rate corresponds to a 3-month (1-year) bond. In both cases, interest rates correspond to yearly returns. 
Table 3

Sensitivity of the Debt Positions (and Interest Rates) to the Persistence of the Shocks

Persistence Debt Positions $\left(\frac{p^{j}\left(g_{\text {low }} s_{\text {high }}\right) b^{j}}{y_{g_{\text {low }} s_{\text {high }}}}\right)$

Short Term Interest Rates $(\%)$

A. War Example (2 States), Yearly Calibration

\begin{tabular}{ccccc} 
& $j=1$ & $j=30$ & $g_{\text {low }}$ & $g_{\text {high }}$ \\
\cline { 2 - 5 }$\tilde{\mathrm{n}}=1$ & -1.77 & 2.26 & 1.46 & 9.64 \\
$\tilde{\mathrm{n}}=2 / 3$ & -1.06 & 1.30 & -2.99 & 11.05 \\
$\tilde{\mathrm{n}}=1 / 3$ & -.078 & 0.91 & -7.29 & 12.45
\end{tabular}

B. Business Cycle Example (4 States), Yearly Calibration

\begin{tabular}{ccccccccc} 
& $j_{1}$ & $j_{2}$ & $j_{3}$ & $j_{4}$ & $g_{\text {low }}, s_{\text {high }}$ & $g_{\text {low }}, s_{\text {low }}$ & $g_{\text {high }}, s_{\text {high }}$ & $g_{\text {high }}, s_{\text {low }}$ \\
\cline { 2 - 8 } & & & & & & & & \\
$\tilde{\mathrm{n}}=1$ & -24.62 & 71.96 & -171.89 & 125.12 & 1.81 & 2.04 & 1.99 & 2.23 \\
$\tilde{\mathrm{n}}=2 / 3$ & -19.46 & 65.54 & -186.54 & 141.01 & 1.41 & 1.96 & 2.06 & 2.64 \\
$\tilde{\mathrm{n}}=1 / 3$ & -9.01 & 139.78 & -393.52 & 263.30 & 1.00 & 1.88 & 2.13 & 3.06
\end{tabular}

Note: $\rho$ is a parameter measuring the closeness of the matrix used in each row, $\mathrm{M}_{\rho}$, to an iid transition matrix, $M_{\rho}=\rho M+(1-\rho) I I D$, where IID refers to an iid transition matrix and $M$ corresponds to the transition matrix arising from the different calibrations. The risk aversion in the 2-states example is 2 (correspond to second example in table 1.A yearly calibration); in the 4-states example is 1 (corresponds to the first example in table 2, Chari et. al. (1995) calibration). In the 4-states example the maturities that were used to implement the Ramsey allocation varies from case to case; $\rho=1: J=\left(j_{1}\right.$ $\left.\mathrm{j}_{2} \mathrm{j}_{3} \mathrm{j}_{4}\right)=\left(\begin{array}{llll}1 & 4 & 13 & 30\end{array}\right) ; \rho=2 / 3: \mathrm{J}=\left(\begin{array}{llll}1 & 2 & 5 & 30\end{array}\right) ; \rho=1: \mathrm{J}=\left(\begin{array}{llll}1 & 2 & 3 & 29\end{array}\right)$. In all cases the short-term interest rate correspond to the 1-year bond. 

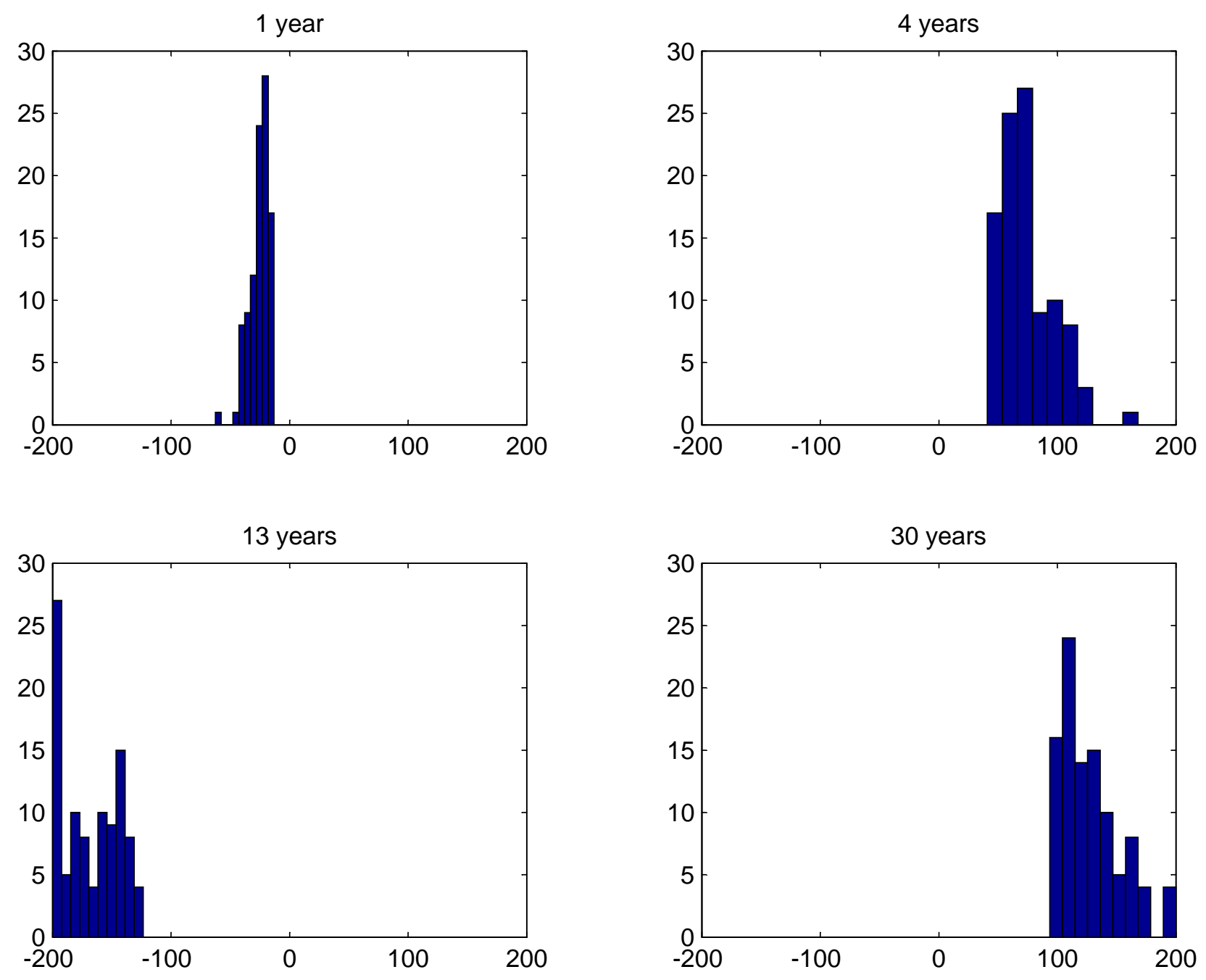

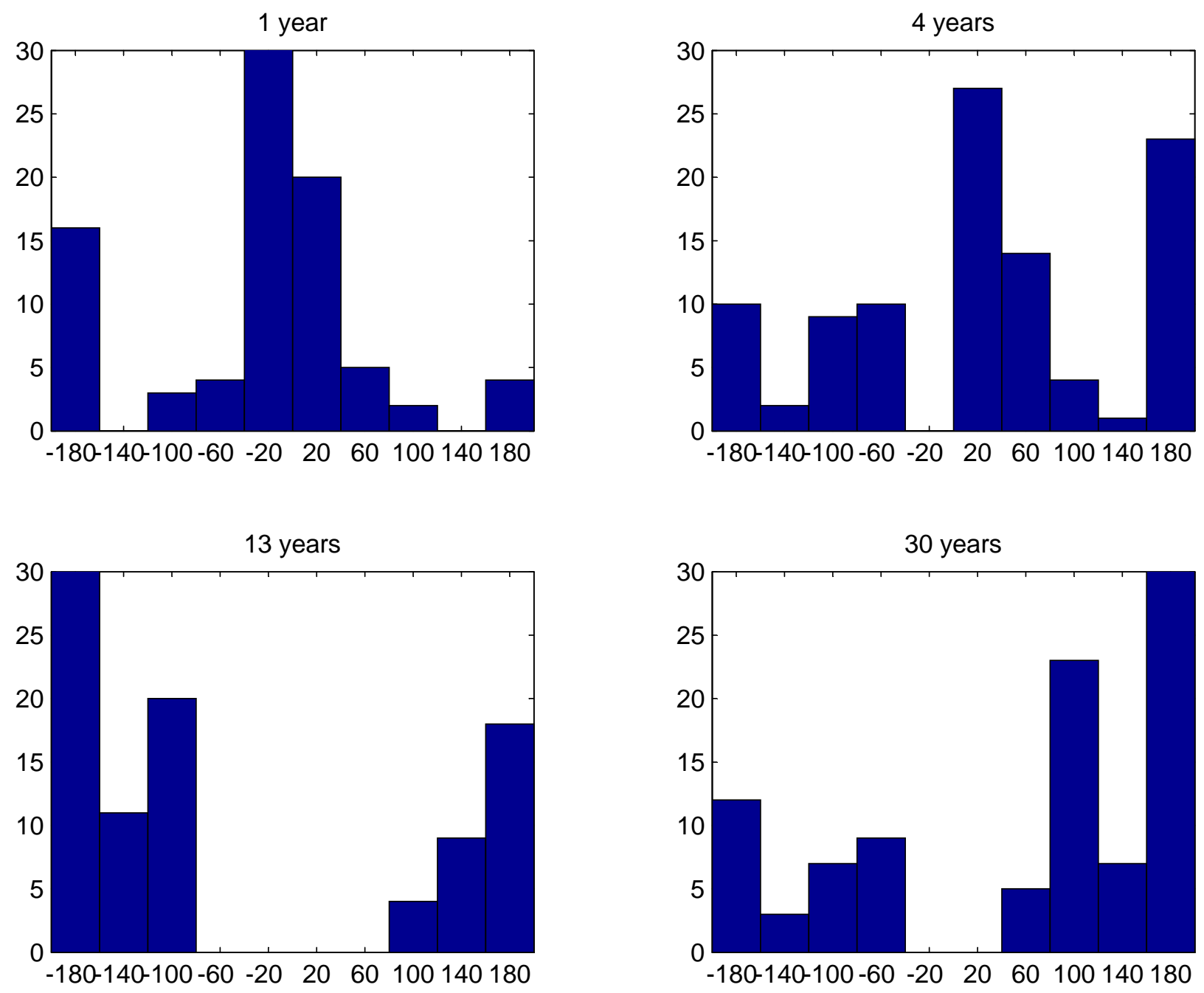

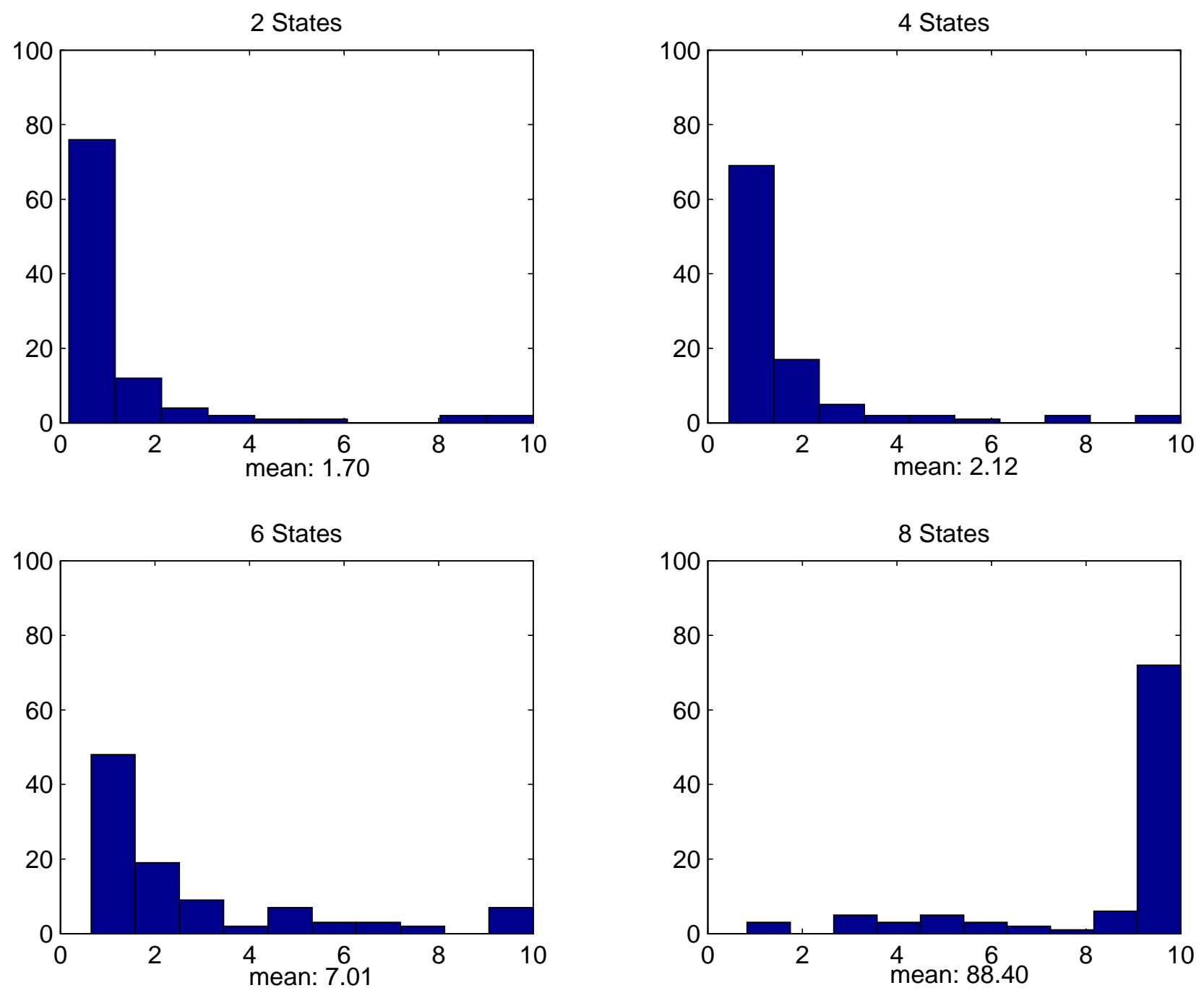